\title{
Cardiovascular fitness and cardiovascular risk factors among obese men and women aged 58 years and older, in Portugal
}

\author{
RÔMULO ARAÚJO F., ${ }^{1,2}$, EDILSON SERPELONI C. ${ }^{2}$, \\ ENIO R. VAZ R. ${ }^{2}$, RENATA SELVATICI BORGES J. ${ }^{2}$, \\ ANALIZA MÓNICA SILVA³, CLÁUDIA SOFÍA MINDERICO ${ }^{3}$, \\ PAULO MANUEL ROCHA ${ }^{3}$, HELENA SANTA-CLARA ${ }^{3}$, \\ FÁTIMA BAPTISTA ${ }^{3}$, LUIS BETTENCOURT SARDINHA ${ }^{3}$
}

Department of Physical Education, Center of

Science and Technology. UNESP Univ Estadual

Paulista, Presidente Prudente, Brazil.

${ }^{2}$ Metabolism, Nutrition and Exercise Laboratory,

Physical Education and Sport Center, Universidade Estadual de Londrina, Londrina, Brazil.

${ }^{3}$ Exercise and Health Laboratory, Faculty of Human Movement, Universidade Tecnológica de Lisboa, Lisboa, Portugal.

Conflict of Interest: There was no potential conflicts of interest.

Received November 17, 2011. Accepted May 9, 2012.

Correspondence: Edilson Serpeloni Cyrino, PhD. Metabolism, Nutrition and Exercise Laboratory. Center of Physical

Education and Sport. Universidade Estadual de Londrina. Rod. Celso Garcia Cid, km 380. CEP 86051. 990 - Londrina, PR - Brazil. E-mail: emcyrino@uel.br

\section{ABSTRACT}

Background: A better physical fitness may have survival advantages in adults. Aim: To analyze the relationship between cardiorespiratory fitness and cardiovascular risk factors among obese subjects aged 58 years and older. Material and Methods: Cardiorespiratory fitness using the six-minute walk test, body composition by dual-energy $x$-ray absorptiometry and blood pressure were measured in a non-representative sample of 76 obese Portuguese subjects aged 58 to 87 years (55 women). Participants were stratified in tertiles of walking capacity according to the six-minute walk test. Results: Six minutes walk test results were negatively correlated with percentage body fat $(r=-0.28 ; p=0.012)$ and systolic blood pressure $(r=-0.23$; $p=0.045)$. Participants located in the lowest tertile for the six minutes walk test had an odds ratio of 4.34 (95\% confidence intervals: 1.02-18.43) for elevated blood pressure. Conclusions: A lower six minutes walk test result is associated with a higher risk for high blood pressure.

(Rev Med Chile 2012; 140: 1164-1169).

Key words: Aged; Hypertension; Obesity; Physical fitness.

\section{Asociación entre el test de caminata de seis minutos y factores de riesgo cardiovascular en portugueses obesos}

Antecedentes: Una mejor condición física se asocia a mejor sobrevida en adultos. Objetivos: Estudiar la relación entre condición física y factores de riesgo cardiovascular en obesos mayores de 58 años. Material y Métodos: Se midió la capacidad cardiorrespiratoria mediante la prueba de caminata de seis minutos, composición corporal mediante densitometría de doble fotón y presión arterial en una muestra no representativa de 76 portugueses de 58 a 87 años (55 mujeres). Los participantes se estratificaron en terciles de acuerdo a los resultados de la prueba de seis minutos. Resultados: Los resultados de la prueba de caminata de seis minutos se correlacionaron negativamente con el porcentaje de grasa corporal $(r=-0,28 ; p=0,012)$ y presión sistólica $(r=-0,23 ; p=0,045)$. Los participantes ubicados en el tercil más bajo de la prueba de caminata de seis minutos tenían una razón de riesgo para hipertensión arterial de 4,34 (intervalos de confianza de 95\%: 1,02-18,43). Conclusiones: Una prueba de caminata de seis minutos con bajos resultados se asocia a un mayor riesgo de hipertensión arterial. 
A geing is an inevitable process of human development, which is composed by many physical transformations, such as decrease of muscle mass (sarcopenia) and increase of adiposity ${ }^{1-3}$. These changes play a critical role in quality of life, physical status ${ }^{4-6}$ and are positively associated with higher cardiovascular risk and mortality ${ }^{7}$. Thus, in both developed and developing nations higher age is positively associated with higher occurrence of unhealthy outcomes, such as obesity ${ }^{8}$, arterial hypertension ${ }^{9,10}$ and metabolic syndrome ${ }^{11}$.

On the other hand, although these inevitable physiologic processes have an important role in the development of chronic diseases in elderly populations, behavioral variables such as a reduced physical activity level (PAL) may have a crucial role in the development of these diseases ${ }^{12-15}$.

Higher PAL is beneficially associated with many health indicators such as lower blood pressure values and reduced insulin resistance, and also has a strong relationship with higher physical fitness ${ }^{16}$. Then, due to this relationship between physical fitness (maximum oxygen uptake) and PAL, cardiorespiratory fitness can be utilized as a cardiovascular risk indicator in elderly populations, and in turn, field tests to measure cardiorespiratory fitness could be applied by health professionals as prevention strategies for screening individuals at risk.

Treadmill tests with incremental protocols and maximum oxygen uptake are gold standards for cardiorespiratory fitness measurements. This method presents elevated cost as well as requires equipments, and for this reason, it cannot be used in large populations. On the other hand, higher cardiorespiratory fitness can be indicated by sixminute walk test (6MWT). The 6MWT is a simple and inexpensive procedure which has a strong relationship with maximum oxygen uptake in elderly populations ${ }^{17}$. However, there are no cutoffs for 6MWT performance in this population and its relationship with cardiovascular risk factors must be clarified among elderly populations.

The inverse relationship between higher cardiorespiratory fitness and lower cardiovascular risk is clear among normal subjects; however, it is not clear whether this relationship occurs in obese subjects. Thus, the purpose of the present study was to analyze the relationship between cardiorespiratory fitness, indicated by $6 \mathrm{MWT}$, and cardiovascular risk factors among obese men and women aged 58 years and older.

\section{Material and Methods}

\section{Subjects}

The studied sample was composed by 76 obese Portuguese individuals ( 21 men and 55 women) with age ranging from 58 to 87 years. In the present study we defined obesity as percentage of body fat $\geq 25$ and $\geq 30$, for men and women, respectively. Subjects were informed about the research design and signed a consent form according to the regulations of the Ethical Committee of the Faculty of Human Kinetics, Technical University of Lisbon. After a fasting of 12 hours, subjects came to the laboratory where all measurements and testing were carried out on the same morning.

\section{Anthropometry}

After voiding, body weight and height were measured on an electronic scale with a stadiometer (SECA, Hamburg, Germany). Weight was recorded to the nearest $0.01 \mathrm{~kg}$ and height nearest 0.1 $\mathrm{cm}$ according to the procedures described by Gordon et al. ${ }^{18}$. Waist circumference was measured on standing subjects with a tape passing mid-way between the lowest rib, and the iliac crest ${ }^{19}$. Body mass index (BMI) in kilograms per squared meter was calculated from weight $(\mathrm{kg})$ and height $(\mathrm{m})$. All participants were wearing minimal clothing during the measurements.

\section{Cardiorespiratory fitness}

The cardiorespiratory fitness was estimated through the six-minute walk test (6MWT). The test followed the protocol of the Senior Fitness Test and consisted of walking around a rectangle of $20 x 5 y d$ (i.e., 50 -yd) on a flat surface, and cones were used to mark the corners and perimeter of the rectangle. The $6 \mathrm{MWT}$ is used to measure the maximum distance that a person can walk in 6 minutes. The test was administered by experienced appraisers and the participants received verbal encouragement. For analysis effect the maximum distance traveled was established in meters. The results reached in $6 \mathrm{MWT}$ (meters) were computed and stratified into tertiles according to gender. Thus, regarding 6MWT length, the sample was distributed as highest (HIG-P), middle (MID-P) 
and lowest (LOW-P) performance for men (HIG$\mathrm{P}: \geq 615.40$ m; MID-P: 615.39 - 560.79m; LOW-P: $\leq 560.78 \mathrm{~m}$ ) and women (HIG-P: $\geq 552.96 \mathrm{~m}$; MID-P: 552.95 - $497.41 \mathrm{~m}$; LOW-P: $\leq 497.40 \mathrm{~m}$ ).

\section{Blood pressure}

Blood pressure (BP) measurements were obtained by a trained technician with aneroid/columnmercury sphygmomanometer and were standardized for cuff size and position. Measurements were made on three separate visits. At each visit, after 15 minutes of sitting rest, $\mathrm{BP}$ was measured in the right arm in the sitting position three times, with two minute between readings. The mean of three consecutive readings was used as the examination value day and the mean $\mathrm{BP}$ of all screening visits was used as final BP. Hypertension was defined as systolic blood pressure (SBP) $\geq 140 \mathrm{mmHg}$ and/ or diastolic blood pressure (DBP) $\geq 90 \mathrm{mmHg}$.

\section{Body composition}

To estimate body fat mass (FM), fat free mass (FFM), percentage of fat (\%FM), and fat trunk (FT), dual-energy x-ray absorptiometry (DXA) measurements were made with a total body scanner (QDR-1500, pencil-beam mode, software version 5.67 enhanced whole-body analyses; Hologic, Waltham, MA, USA) that measured the attenuation of X-rays pulsed between 70 and 140 $\mathrm{kV}$ synchronously with the line frequency for each pixel of the scanned image. Following the protocol for DXA described by the manufacturer, a step phantom with six fields of acrylic and aluminum of varying thickness and known absorptive properties was scanned alongside each subject to serve as an external standard for the analysis of different tissue components. After removing all objects suspected or known to contain metal, participants were positioned supine on the scanning table, by the same laboratory technician. The analyses were executed according to the operator's manual using the standard analysis protocol. Based on ten subjects, the coefficient of variation in our laboratory for FM was $2.9 \%$ and for FFM was $1.7 \%$.

\section{Statistical analysis}

Initially, normality was assessed and rejected (Kolmogorov-Smirnov's test). Thus, numerical variables were compared through Mann-Whitney tests and the Spearman's rank indicated the relationship among the analyzed variables. The chisquared test $\left(\chi^{2}\right)$ was used to evaluate associations. After the $\chi^{2}$ use, the logistic regression, represented by the odds ratio (OR) and 95\% confidence interval $\left(\mathrm{OR}_{95 \% \mathrm{CI}}\right)$, was carried out. Statistical software SPSS 16.0 was used for all data management and the significance was set at $5 \%$.

\section{Results}

The sample studied indicated that across the genders, men presented both less body fat percentage $(29.2 \%)$ and higher performance $(\sim 13 \%)$ in the 6MWT than women (Table 1).

In both genders the higher performance in 6MWT was negatively correlated with age (male:

Table 1. General characteristics of the studied sample $(\mathbf{n}=76)$

\begin{tabular}{|c|c|c|c|c|}
\hline Variables & $\begin{array}{c}\text { Male }(n=21) \\
\text { Median (IR) }\end{array}$ & $\begin{array}{c}\text { Female }(n=55) \\
\text { Median (IR) }\end{array}$ & $\mathbf{Z}$ & $\mathbf{P}$ \\
\hline Age (years) & $71 \quad(10)$ & $71 \quad(10)$ & -0.111 & 0.912 \\
\hline SBP $(\mathrm{mmHg})$ & $144 \quad(30)$ & 148 & -0.360 & 0.719 \\
\hline $\mathrm{DBP}(\mathrm{mmHg})$ & $77 \quad(20)$ & $71 \quad(18)$ & -2.255 & 0.024 \\
\hline$\% B F$ & $29.8(5.2)$ & $42.1 \quad(6.5)$ & -5.930 & 0.001 \\
\hline BMI $\left(\mathrm{kg} / \mathrm{m}^{2}\right)$ & $27.6(2.9)$ & $27.6 \quad(6.1)$ & -0.796 & 0.426 \\
\hline$W C(\mathrm{~cm})$ & $99.4(8.1)$ & $99.8(15.4)$ & -0.250 & 0.803 \\
\hline FT (kg) & $13.3(3.8)$ & $14.6 \quad(7.4)$ & -0.203 & 0.839 \\
\hline 6MWT (m) & $600(92.5)$ & $533 \quad(104)$ & -3.550 & 0.001 \\
\hline
\end{tabular}

$6 \mathrm{MWT}=$ six minutes walk test; $\mathrm{IR}=$ interquartile range; $\mathrm{BMI}=$ body mass index; $\% \mathrm{BF}=$ body fat percentage; $\mathrm{WC}=$ waist circumference; $\mathrm{FT}=$ fat trunk; $\mathrm{SBP}=$ systolic blood pressure; $\mathrm{DBP}=$ diastolic blood pressure. 
Table 2. Relationship between physical fitness and cardiovascular risk factors $(\mathbf{n}=\mathbf{7 6})$

\begin{tabular}{|lcccccc|}
\hline & \multicolumn{2}{c}{ Hemodynamic } & \multicolumn{2}{c|}{ General Adiposity } & \multicolumn{2}{c|}{ Central Adiposity } \\
& SBP & DBP & BMI & \%BF & WC & FT \\
\hline 6MWT & -0.23 & 0.12 & -0.08 & -0.28 & -0.04 & -0.04 \\
\hline$P$ & 0.045 & 0.293 & 0.452 & 0.012 & 0.680 & 0.678 \\
\hline
\end{tabular}

$6 \mathrm{MWT}=$ six minutes walk test; $\mathrm{BMI}=$ body mass index; \%BF= body fat percentage; $\mathrm{WC}=$ waist circumference; $F \mathrm{FT}=$ fat trunk; $\mathrm{SBP}=$ systolic blood pressure; $\mathrm{DBP}=$ diastolic blood pressure.

Table 3. Age and gender adjusted odds ratios ( $95 \%$ confidence intervals) for association between hypertension and 6MWT performance $(n=76)$

\begin{tabular}{|c|c|c|c|c|}
\hline \multirow{2}{*}{\multicolumn{2}{|c|}{ Independent variable }} & \multicolumn{2}{|c|}{ Outcome: arterial hypertension } & \multirow[b]{2}{*}{$\mathbf{p}$} \\
\hline & & n (\%) & OR $\left(\right.$ OR $\left._{95 \% \mathrm{Cl}}\right)$ & \\
\hline \multirow[t]{3}{*}{$6 \mathrm{MWT}$} & LOW-P & 20 (76.9) & $4.34(1.02-18.3)$ & 0.046 \\
\hline & MID-P & $19(70.4)$ & $3.62(1.01-13.01)$ & 0.048 \\
\hline & HIG-P & $9(39.1)$ & 1.0 & --- \\
\hline
\end{tabular}

$\mathrm{OR}=$ odds ratio; $95 \% \mathrm{Cl}=95 \%$ confidence interval; $\mathrm{LOW}-\mathrm{P}=$ lowest performance in $6 \mathrm{MWT}$; MID-P= middle performance in $6 \mathrm{MWT}$; LOW-P= highest performance in 6MWT.

$\mathrm{r}=-0.62 ; p=0.002$ / female: $\mathrm{r}=-0.52 ; p=0.001)$. Moreover, age was related with SBP $(\mathrm{r}=0.36 ; p=$ $0.006)$ and $\mathrm{FT}(\mathrm{r}=0.31 ; p=0.021)$, only in female gender. The nonparametric correlation indicated that there was a statistically significant relationship (both genders) between higher physical fitness and lower SBP and \%BF (Table 2).

The chi-square test indicated that there was an association between highest 6MWT performance and hypertension presence $\left(\chi^{2}=7.193 ; p=0.007\right)$. However, there was no such association for elevated waist circumference $\left(\chi^{2}=0.085 ; p=0.771\right)$, and highest FT group $\left(\chi^{2}=0.000 ; p=0.984\right)$. Thus, in the logistic regression (Table 3 ), the magnitudes of these associations were assessed, and significant values of OR in lowest performance' group were found (Middle tertile: $\mathrm{OR}=3.62\left[\mathrm{OR}_{95 \% \mathrm{CI}} 1.01\right.$ 13.01]; $\mathrm{p}=0.048$ and Lowest tertile: $\mathrm{OR}=4.34$ $\left.\left[\mathrm{OR}_{95 \% \mathrm{CI}} 1.02-18.39\right] ; \mathrm{p}=0.046\right)$.

\section{Discussion}

Studies suggest that aging causes a progressive decrease in physical function due to a continued decline in muscle mass ${ }^{20}$ and strength ${ }^{21}$. These impairments affect activities of daily living and quality of life. Moreover, frailty is associated with limitations in basic or instrumental activities of daily living ${ }^{22}$. Therefore, the higher PAL/physical fitness could present a protective effect over all these unhealthy outcomes among older people. Apparently, this age effect on 6MWT is influenced by gender, because men have more elevated performance than women. This result agrees with previous data, where among subjects aged 40 to 80 years, Enright and Sherrill ${ }^{17}$ recorded a median $6 \mathrm{MWT}$ distance of $576 \mathrm{~m}$ for men $(\mathrm{n}=117$, median age $=59.5$ years) and a median distance of 494 $\mathrm{m}$ for women $(\mathrm{n}=173$, median age $=62.0$ years $)$. This gender effect over 6MWT performance could be justified because men have more muscle mass than women, and in turn the sarcopenia would affect more strongly women performance.

The negative relationship observed between higher adiposity and lower physical fitness agrees with previous data observed in adolescents ${ }^{23}$ and adults $^{24}$. Given the existence of these results in different age groups, it may indicate that it occurs throughout life, thus, low scores in 6MWT could also be utilized as indicators of higher cardiovascular risk among elderly. However, the absence of internationally recognized cutoffs for 6MWT performance among elderly individuals constitutes a limitation which must be focused in further studies.

Abdominal adiposity is associated with a hig- 
her occurrence of cardiovascular disease $\mathrm{e}^{25}$ because it is associated with increased release of adipokines related to a variety of inflammatory processes in the human organism ${ }^{26,27}$. Thus, the existence of an inverse association between central adiposity and $6 \mathrm{MWT}$ would indicate an additional screening characteristic of cardiovascular risk. However, the lack of association between FT/WC and 6MWT observed in our study is in disagreement with previous cross-sectional observations ${ }^{28}$, which showed a significant association between fat mass and body fat distribution with reported disability and physical performance. This dissociation could be confounded by \%BF, because this sample was composed only by obese subjects.

In the present study, even among obese subjects, less fit subjects were four times more likely to have hypertension than those who were more fit, and this trend was also observed in the middle group for $6 \mathrm{MWT}$ performance. In fact, there is previous data in the literature indicating that physical exercise increases nitric oxide production without reduction in body weight ${ }^{29}$. Additionally, also without modifications in body composition, physical exercise decreases blood concentration of inflammatory adipokines related to insulin resistance ${ }^{30}$, which has a relevant burden in the development of endothelial dysfunction ${ }^{26}$. Our findings suggest that the above mentioned mechanisms occur also in obese older adults.

Utilization of accurate methods to assess body composition is a strength point of the study; however, its limitations must be recognized. First, we admit that the small sample size could reduce the power to detect differences, and the cross-sectional design that cannot establish temporal relationship (causality) are the main limitations of this study. Second, ageing is a potential confounder related to analyzed outcomes and, therefore, future investigations should stratify the sample into different age groups, as well as, it would be of interest to correlate physical behaviour with social and working earning capacity. Finally, other potential confounders should be taken into account in future studies, such as diagnosis of type 2 diabetes mellitus and smoking habits.

In conclusion, independently of obesity presence, this study identified an inverse association between higher 6MWT performance and decreased hypertension rate among Portuguese adults aged 58 years and older.
Acknowlegements: We would like to express thanks to all the participants for their engagement in this study. Part of this work was conducted while E.S.C. was a CNPq/Brazil post-doctoral fellowship at the Faculty of Human Kinetics, Technical University of Lisbon, Portugal (Process number 202199/2007-0).

\section{References}

1. Evans WJ, Campbell WW. Sarcopenia and age-related changes in body composition and functional capacity. J Nutr 1993; 123: 465-8.

2. Visser M, Pahor M, Tylavsky F, Kritchevsky SB, Cauley $J A$, Newman AB, et al. One- and two-year change in body composition as measured by DXA in a populationbased cohort of older men and women. J Appl Physiol 2003; 94: 2368-74.

3. Zamboni M, Zoico E, Scartezzini T, Mazzali G, Tosoni P, Zivelonghi A, et al. Body composition changes in stableweight elderly subjects: the effect of sex. Aging Clin Exp Res 2003; 15: 321-7.

4. Baumgartner RN. Body composition in healthy aging. Ann N Y Acad Sci 2000; 904: 437-48.

5. Byles JE. Fit and well at eighty: defying the stereotypes of age and illness. Ann N Y Acad Sci 2007; 1114: 10720.

6. Visser M, Harris TB, Langlois J, Hannan MT, Roubenoff $\mathrm{R}$, Felson DT, et al. Body fat and skeletal muscle mass in relation to physical disability in very old men and women of the Framingham Heart Study. J Gerontol Med Sci 1998; 53A: M214-M221.

7. Sui X, LaMonte MJ, Laditka JN, Hardin JW, Chase N, Hooker SP, Blair SN. Cardiorespiratory fitness and adiposity as mortality predictors in older adults. JAMA 2007; 298: 2507-16.

8. Davison KK, Ford ES, Cogswell ME, Dietz WH. Percentage of body fat and body mass index are associated with mobility limitations in people aged 70 and older from NHANES III. J Am Geriatr Soc 2002; 50: 1802-9.

9. Callow AD. Cardiovascular disease 2005 - the global picture. Vascul Pharmacol 2006; 45: 302-7.

10. Rocha E, Silva AM, Gouveia-Oliveira A, Nogueira P. Hipertensão sistólica isolada: epidemiologia e impacto na prática clínica. Rev Port Cardiol 2003; 22: 7-23.

11. Lechleitner M. Obesity and the metabolic syndrome in the elderly - a mini-review. Gerontology 2008; 54: 253-9.

12. Fine JT, Colditz GA, Coakley EH, Moseley G, Manson JE, Willet WC, Kawachi I. A prospective study of weight change and health-related quality of life in women. JAMA 1999; 282: 2136-42. 
13. Guo SS, Zeller C, Chumlea WC, Siervogel RM. Aging, body composition, and lifestyle: the Fels Longitudinal Study. Am J Clin Nutr 1999; 70: 405-11.

14. Hughes VA, Frontera WR, Roubenoff R, Evans WJ, Fiatarone Singh MA. Longitudinal changes in body composition in older men and women: role of body weight change and physical activity Am J Clinl Nutr 2002; 76: 473-81.

15. DiPietro L. Physical activity in aging: changes in patterns and their relationship to health and function. J Gerontol A Biol Sci Med Sci 2001; 2 (Spec No): 13-22.

16. Church TS, LaMonte MJ, Barlow CE, Blair SN. Cardiorespiratory fitness and body mass index as predictors of cardiovascular disease mortality among men with diabetes. Arch Intern Med 2005; 165: 2114-20.

17. Enright PL, Sherrill DL. Reference equations for the six-minute walk in healthy adults. Am J Respir Crit Care Med 1998; 158 (5 Pt 1): 1384-7.

18. Gordon CC, Chumlea WC, Roche AF. Stature, recumbent length, and weight. In: Lohman TG, Roche AF, Martorell R., editors. Anthropometric standardizing reference manual. Champaign: Human Kinetics, 1988; 3-8.

19. Callaway CW, Chumlea WC, Bouchard C. Circumferences. In: Lohman TG, Roche AF, Martorell R., editors. Anthropometric standardizing reference manual. Champaign: Human Kinetics 1988; 39-54.

20. Roubenoff R, Hughes VA. Sarcopenia: current concepts. J Gerontol A Biol Sci Med Sci 2000; 55: M716-24.

21. Ensrud KE, Nevitt MC, Yunis C, Cauley JA, Seeley DG, Fox KM, Cummings SR. Correlates of impaired function in older women. J Am Geriatr Soc 1994; 42: 481-9.

22. Nourhashémi F, Andrieu S, Gillette-Guyonnet S, Vellas
B, Albarède JL, Grandjean H. Instrumental activities of daily living as a potential marker of frailty: a study of 7364 community-dwelling elderly women (the EPIDOS study). J Gerontol A Biol Sci Med Sci 2001; 56: M448-53.

23. Gutin B, Yin Z, Humphries MC, Barbeau P. Relations of moderate and vigorous physical activity to fitness and fatness in adolescents. Am J Clin Nutr 2005; 81: 746-50.

24. Orsi JV, Nahas FX, Gomes HC, Andrade CH, Veiga DF, Novo NF, Ferreira LM. Impact of obesity on the functional capacity of women. Rev Assoc Med Bras 2008; 54 : 106-9.

25. Laaka TA, Laakasonen DE. Physical activity in prevention and treatment of the metabolic syndrome. Appl Physiol Nutr Metab 2007; 32: 76-88.

26. Huang PL. eNOS, metabolic syndrome and cardiovascuar disease Trends Endocrinol Metab 2009; 20: 295-302.

27. Kotsis V, Stabouli S, Papakatsika S, Rizos Z, Parati G. Mechanisms of obesity-induced hypertension. Hypertens Res 2010; 33: 386-93.

28. Zamboni M, Turcato E, Santana H, Maggi S, Harris TB, Pietrobelli A, et al. The relationship between body composition and physical performance in older women. J Am Geriatr Soc 1999; 47: 1403-8.

29. Zaros PR, Pires CE, Bacci M Jr, Moraes C, Zanesco A. Effect of 6-months of physical exercise on the nitrate/ nitrite levels in hypertensive postmenopausal women. BMC Womens Health 2009; 9: 17.

30. Balducci S, Zanuso S, Nicolucci A, Fernando F, Cavallo $\mathrm{S}$, Cardelli $\mathrm{P}$, et al. Anti-inflammatory effect of exercise training in subjects with type 2 diabetes and the metabolic syndrome is dependent on exercise modalities and independent of weight loss. Nutr Metab Cardiovasc Dis 2010; 20: 608-17. 